\title{
Effects of modification with glutaraldehyde on the mechanical properties of wood
}

\section{Zefang Xiao, Yanjun Xie, Holger Militz and Carsten Mai*}

Wood Biology and Wood Products, Burckhardt-Institute, Georg August University of Göttingen, Göttingen, Germany

\author{
* Corresponding author. \\ Wood Biology and Wood Products, Burckhardt-Institute, \\ Georg August University of Göttingen, Büsgenweg 4, \\ D37077 Göttingen, Germany \\ Phone: +49-551-3919807 \\ Fax: +49-551-399646 \\ E-mail: cmai@gwdg.de
}

\begin{abstract}
Scots pine (Pinus sylvestris L.) sapwood was treated with glutaraldehyde (GA) and magnesium chloride $\left(\mathrm{MgCl}_{2}\right)$ as a catalyst. The effects of treating conditions on the mechanical properties were examined. The weight percent gain (WPG) of thin veneer strips after leaching was highest at $\mathrm{pH}$ 4.0-4.5 and tensile strength measured in zero-span strength and finite-span strength decreased with decreasing $\mathrm{pH}$ in a range of 3.5-5.5. Sole treatment with $\mathrm{MgCl}_{2}$ also gradually decreased the tensile strength up to $25 \%$ with decreasing $\mathrm{pH}$. At a fixed GA concentration (1.2 M), increasing $\mathrm{MgCl}_{2}$ concentration linearly diminished tensile strength. Conversely, increasing $\mathrm{GA}$ at a fixed $\mathrm{MgCl}_{2}$ concentration (1.5\%) displayed the same effect, whereas in both cases zero-span strength loss was higher than finite span-strength loss. GA treatment of Scots pine sapwood stakes did not affect the modulus of rupture and the modulus of elasticity, but significantly reduced work to maximum load in bending and impact bending strength indicating embrittlement of wood. At the same time, compression strength increased with increasing WPG of GA. It is assumed that embrittlement caused by hydrolysis and crosslinking of cell wall polymers is compensated by enhanced compression strength thereby resulting in unchanged bending strength.
\end{abstract}

Keywords: bending strength; compression strength; glutaraldehyde; tensile strength; wood modification.

\section{Introduction}

Glutaraldehyde (GA, pentane-1,5-dial) is a dialdehyde which can in principle react with four hydroxyl groups and crosslink cell wall polymers in wood (Xiao et al. 2009). Three types of catalyst were applied for GA modification of wood: (a) metal based Lewis acids such as magnesium chloride $\left(\mathrm{MgCl}_{2}\right)$ and zinc chloride (Weaver et al. 1960; Xiao et al.
2009), (b) quaternary ammonium compounds such as phenyldimethylammonium chloride and pyridinium chloride (Weaver et al. 1960), and (c) sulfur dioxide $\left(\mathrm{SO}_{2}\right)$ gas (Yasuda and Minato 1994; Yasuda et al. 1994). Wood modification with GA has been reported to enhance water related properties concerning reduced water uptake and moisture sorption, increased dimensional stability and enhanced resistance to decay organisms. These properties are attributed to the ability of GA to block hydroxyl groups, to bulk the cell wall and to crosslink the matrix polymers (Weaver et al. 1960; Yasuda and Minato 1994; Yasuda et al. 1994; Xiao et al. 2009). The moduli of elasticity (MOE) and of rupture (MOR) were hardly changed through GA treatment (Yasuda and Minato 1994), but limited information is available on the influence of GA treatment on other strength properties such as toughness, particularly when the reaction was catalyzed by Lewis acids. It is assumed that GA in combination with one of the catalysts might cause embrittlement of wood as a result of hydrolysis and crosslinking of cell wall polymers.

Treatment of cotton fabrics with formaldehyde enhanced the dimensional stability, but induced brittleness and strength loss. This was attributed to an extreme loss in extensibility, because of the shortness of the formal crosslink (Roff 1958) and acid-catalyzed hydrolysis of the cellulose in the presence of metallic chlorides as catalysts (Nuessle et al. 1955). Some dialdehyde reagents such as glyoxal and glutaraldehyde have displayed their effectiveness in providing cotton fabrics with comparable properties as attained after formaldehyde treatment (Frick and Harper 1982).

Cotton fabrics treated with GA showed a higher degree of crosslinking than those treated with glyoxal under identical conditions. GA forms non-hydrated or hemi-hydrated monomers in water, whereas glyoxal is available as dimer, trimer, 5- or 6-membered ring, or in polymeric form (Fujimura and Okamoto 1961; Frick and Harper 1982; Choi et al. 1999). Therefore, aqueous GA is assumed to exhibit higher sorption ability and reactivity towards cotton owing to its monomeric form as compared to glyoxal (Whipple and Ruta 1974; Choi et al. 1999).

Tensile strength loss of wood has been detected using thin veneer strips to evaluate the effectiveness of wood preservatives (Hartley 1958; Haider and Domsch 1969; Bravery and Grant 1971), to study the degradation of wood during weathering (Raczkowski 1980; Derbyshire and Miller 1981; Evans et al. 2000, 2002), and to monitor strength losses during chemical modification processes (Xie et al. 2007). Treatment of wood with aqueous solutions of metal oxides (chromium trioxide, ferric chloride, and ferric nitrate) was shown to reduce tensile strength of veneer strips. Strength losses up to $40 \%$ were observed as a result of the oxidative 
degradation of thin veneers strips following treatment with ferric salt solutions (Evans and Schmalzl 1989). Generally, chemical modification processes include a curing step at temperatures up to $120^{\circ} \mathrm{C}$. Elevated temperatures can cause oxidative degradation or hydrolysis, particularly when the modification is catalyzed by proton acids (e.g., $\mathrm{HCl}$, acetic acid) or Lewis acids such as $\mathrm{MgCl}_{2}$. Treatment with 1,3dimethylol-4,5-dihydroxyethyleneurea (DMDHEU) with $\mathrm{MgCl}_{2}$ as catalyst caused tensile strength loss of thin pine veneer strips by more than $50 \%$. The losses were attributed to both hydrolysis and crosslinking of cell wall polymers (Xie et al. 2007).

Formaldehyde treatment also induced severe brittleness of wood, but had a minor effect on static strength properties (Stamm 1959; Burmester 1967; Yano et al. 1986). The loss in abrasion resistance of formalized wood correlated with the reduction in swelling and revealed that crosslinking might be a major reason for loss in toughness (Stamm 1959). As observed with GA, wood was shown not to react with formaldehyde in the absence of acid catalysts (Tarkow and Stamm 1953). Acidic catalysis, however, resulted in hydrolysis of cell wall polymers: sulfur dioxide and hydrochloric acid cause degradation of the fiber cell walls and loss of polysaccharide in the absence and presence of formaldehyde (Stevens and Parameswaran 1981a,b). Similarly, the use of Lewis acid catalysts also reduced the mechanical properties of formaldehyde-treated wood (Vihavainen et al. 1980).

Furfurylation of wood with zinc chloride, citric acid or formic acid decreased MOR, abrasion resistance, and toughness and increased MOE (Stamm 1977). Strength losses were attributed to wood degradation by the catalysts; the relative toughness and abrasion resistance was approximately reverse proportional to the logarithm of the zinc chloride concentration. Westin et al. (2004) reported on the decrease in impact strength when Scots pine wood was furfurylated with citric acid or cyclic anhydride as catalysts in a pilot plant. The reduction in impact bending strength amounted to approximately $25 \%$ at $15 \%$ WPG and exceeded $50 \%$ at $32 \%$ WPG as compared to the untreated controls.

Acetylation, in contrast, did not significantly change the mechanical properties such as MOR or MOE, but variable results were obtained between wood species (Tarkow et al. 1946; Bongers and Beckers 2003). The tensile strength of thin veneer strips (100 $\mu \mathrm{m}$ thickness) of Scots pine and lime wood did not change significantly in comparison to untreated controls (Rowell and Banks 1987).

The main objective of this study was to establish the effect of modification with GA and of the individual constituent of the reaction system (catalyst and reactant) at defined $\mathrm{pH}$ levels on the tensile properties of veneers. Static and dynamic properties of solid wood were also assessed after combined treatment with GA and $\mathrm{MgCl}_{2}$.

\section{Materials and methods}

\section{Chemicals}

Glutaraldehyde (GA) was supplied as a 50\% solution in technical quality with $\mathrm{pH}$ values of 3.2-4.2 (BASF AG, Ludwigshafen, Ger- many). Magnesium chloride hexahydrate $\left(\mathrm{MgCl}_{2} \cdot 6 \mathrm{H}_{2} \mathrm{O}\right)$ was of extra purity grade. All other chemicals were of analytical purity grade.

\section{Wood specimens}

Wood veneers measuring $100 \mathrm{~mm} \times 15 \mathrm{~mm} \times 80 \mu \mathrm{m}(\mathrm{L} \times \mathrm{R} \times \mathrm{T})$ were cut from the water saturated sapwood blocks of Scots pine sapwood (Pinus sylvestris L.) with disposable microtome blades (Reichert-Jung, Nussloch, Germany) as previously described (Evans and Banks 1988; Xie et al. 2007). Scots pine sapwood specimens measuring $180 \times 10 \times 10 \mathrm{~mm}^{3}(\mathrm{~L} \times \mathrm{T} \times \mathrm{R})$ were used for determination of bending strength and impact bending strength. Compression strength was determined on blocks measuring $30 \times 20 \times$ $20 \mathrm{~mm}^{3}(\mathrm{~L} \times \mathrm{T} \times \mathrm{R})$.

\section{Treatment of veneers}

Per treatment, 20 veneers were conditioned to equilibrium moisture content at $20^{\circ} \mathrm{C}$ and $65 \% \mathrm{RH}$ and 10 veneers were dried at $103^{\circ} \mathrm{C}$. Subsequently, all 30 veneers were treated with GA and/or $\mathrm{MgCl}_{2} \cdot 6 \mathrm{H}_{2} \mathrm{O}$ in acetate buffer $(0.1 \mathrm{M})$ adjusted to specific $\mathrm{pH}$ values ( $\mathrm{pH}$ meter: $\mathrm{pH}$ 526, Wissenschaftlich-Technische Werkstätten, Weilheim, Germany). Impregnation was performed under vacuum conditions (100 mbar, $30 \mathrm{~min}$ ) and ambient pressure (10 min). After impregnation, the excess treatment solution was blotted off the veneers with tissue paper. The veneers were pre-dried at room temperature $(1 \mathrm{~h})$ and put into an oven pre-heated to $60^{\circ} \mathrm{C}$. The temperature was subsequently increased $\left(1^{\circ} \mathrm{C} \times \mathrm{min}^{-1}\right)$ to $120^{\circ} \mathrm{C}$ and held for $2 \mathrm{~h}$ for final curing. All treated specimens were rinsed with running tap water (approximately $40^{\circ} \mathrm{C}$ ) for $2 \mathrm{~h}$ to remove unreacted GA. The weight percent gain (WPG) caused by GA was determined after curing and rinsing of the 10 veneers which were dried prior to the treatment. These 10 veneers were not subject to strength testing. The treatment solutions were as follows $\left(\mathrm{MgCl}_{2} \cdot 6 \mathrm{H}_{2} \mathrm{O}\right.$ concentration is given as w/w): (1) $1.2 \mathrm{M} \mathrm{GA}$ alone or with $1.5 \%$ $\mathrm{MgCl}_{2} \cdot 6 \mathrm{H}_{2} \mathrm{O}$ at $\mathrm{pH}$ of $3.5,4.0,4.5,5.0$, and 5.5, respectively; (2) $1.5 \% \mathrm{MgCl}_{2} \cdot 6 \mathrm{H}_{2} \mathrm{O}$ at $\mathrm{pH}$ of $4.0,4.5,5.0$, and 5.5, respectively; (3) $1.2 \mathrm{M} \mathrm{GA}$ with $0 \%, 0.5 \%, 1.5 \%, 2.5 \%$, and $3.5 \% \mathrm{MgCl}_{2} \cdot 6 \mathrm{H}_{2} \mathrm{O}(\mathrm{pH}$ 4.5); (4) $0.4 \mathrm{M}, 1.2 \mathrm{M}$, and $2.0 \mathrm{M}$ GA with $1.5 \% \mathrm{MgCl}_{2} \cdot 6 \mathrm{H}_{2} \mathrm{O}(\mathrm{pH}$ 4.5); (5) $0.4 \mathrm{M}(0.5 \%), 1.2 \mathrm{M}(1.5 \%)$, and $2.0 \mathrm{M}$ (2.5\%) GA $\left(\mathrm{MgCl}_{2} \cdot 6 \mathrm{H}_{2} \mathrm{O}\right)(\mathrm{pH} 4.5)$. Ten veneers treated with acetate buffer $(\mathrm{pH}$ 4.5) served as controls and the average tensile strength value was set to $100 \%$. The veneers used for the specific treatments (1-5) and the controls were cut from one individual block in each case. Prior to tensile testing, the veneers were conditioned at $20^{\circ} \mathrm{C}$ and $65 \%$ $\mathrm{RH}$; their thickness was determined using a dial gauge micrometer (Mitutoyo, Mexico).

\section{Treatment of solid wood specimens}

The solid wood stakes prepared for bending and impact test were impregnated with $1.2 \mathrm{M} \mathrm{GA}$ and $0.5 \%, 2.5 \%$, and $3.5 \%$ $\mathrm{MgCl}_{2} \cdot 6 \mathrm{H}_{2} \mathrm{O}$, respectively, and $0.4 \mathrm{M}(1.5 \%), 1.2 \mathrm{M}(1.5 \%)$ and $2.0 \mathrm{M}(1.5 \%) \mathrm{GA}\left(\mathrm{MgCl}_{2} \cdot 6 \mathrm{H}_{2} \mathrm{O}\right)$ in aqueous acetate buffer $(0.1 \mathrm{M}$, $\mathrm{pH} 4.5)$ using vacuum (100 mbar, $1 \mathrm{~h})$ and pressure (10 bar, $2 \mathrm{~h}$ ). The blocks for the compression test were impregnated with $0.4 \mathrm{M}$ (0.5\%), $1.2 \mathrm{M}(1.5 \%)$, and $2.0 \mathrm{M}(2.5 \%) \mathrm{GA}\left(\mathrm{MgCl}_{2} \cdot 6 \mathrm{H}_{2} \mathrm{O}\right)$ in aqueous acetate buffer $(0.1 \mathrm{M}, \mathrm{pH} 4.5)$ as described above. Specimens treated solely with aqueous acetate buffer $(0.1 \mathrm{M}, \mathrm{pH} 4.5)$ served as controls for all mechanical tests. After impregnation, excess treatment solution was blotted off the wood specimens with tissue paper and the wood specimens were air dried (1 week). Sub- 
sequently, the specimens were pre-cured at $80^{\circ} \mathrm{C}(48 \mathrm{~h})$ and finally cured at $120^{\circ} \mathrm{C}(48 \mathrm{~h})$.

\section{Zero-span tensile strength of micro-veneers (z-strength)}

Zero-span tensile strength losses of the veneers were determined with a Pulmac paper tester (Pulmac International Inc., Middlesex, CT, USA) as described previously (Derbyshire and Miller 1981; Evans and Schmalzl 1989; Xie et al. 2007). The rate of loading was set to $70 \mathrm{kPa} \mathrm{s}^{-1}$. The initial clamping pressure was set to $0.52 \mathrm{MPa}$ for untreated veneers and to $0.2 \mathrm{MPa}$ for treated veneers. Tensile strength retention was related to untreated controls. For each treatment 10 veneers were tested; the veneer was cut into four pieces to measure tensile strength and an average value was calculated for each veneer.

\section{Finite span tensile strength of micro-veneers (f-strength)}

Finite-span tensile strength ( $25 \mathrm{~mm}$ clamps width) was determined with a universal testing machine Zwick/Z010 (Zwick, Ulm, Germany) at an elongation rate of $0.25 \mathrm{~mm} \mathrm{~min}^{-1}$. Tensile strength retention was related to untreated veneers (controls). For each treatment, 10 veneers were tested; the veneer was cut into two pieces to measure tensile strength and an average value was calculated for each veneer.

\section{Mechanical properties of solid wood}

The bending properties, modulus of rupture (MOR) and modulus of elasticity (MOE), and resulting work to maximum load in bending, were determined at a test speed of $1.5 \mathrm{~mm} \mathrm{~min}^{-1}$ according to DIN 52186 (1978) with the same universal testing machine as indicated above. Impact bending strength was measured according to DIN 52189 (1981). The axial compression strength was determined at a test speed of $0.9 \mathrm{~mm} \mathrm{~min}^{-1}$ on a Zwick/Roell ZMART.PRO $100 \mathrm{kN}$ testing machine (Zwick GmbH \& Co. KG, Ulm, Germany) according to DIN 52185. At least 20 replicates were used per treatment
Table 1 Density and moisture content at $65 \% \mathrm{RH}$ and $20^{\circ} \mathrm{C}$ of stakes used to determine MOR and MOE according to DIN 52186 (1978).

\begin{tabular}{lcc}
\hline \multicolumn{1}{c}{ Treatment } & $\begin{array}{c}\text { Density } \\
\left(\mathrm{g} \mathrm{cm}^{-3}\right)\end{array}$ & $\begin{array}{c}\text { Moisture content } \\
(\%)\end{array}$ \\
\hline Acetate buffer (control) & 0.48 & 10.7 \\
0.4 M GA & 0.49 & 8.8 \\
1.2 M GA & 0.51 & 6.9 \\
2.0 M GA & 0.52 & 6.1 \\
\hline
\end{tabular}

and test. Prior to testing, the specimens were condition at $65 \% \mathrm{RH}$ and $20^{\circ} \mathrm{C}$ and the density was determined (Table 1 ).

\section{Statistical analysis}

Software used for statistical analysis was OriginLab 8.0 (OriginLab Corporation, Northampton, MA, USA). The data were first tested for normal distribution (Shapiro-Wilk test) and one-way analysis of variance (Tukey test) was used to compare the mean values. The comparison of $\mathrm{z}$-strength and f-strength of specimens, which received the same treatment, is based on the paired sample t-test.

\section{Results and discussion}

\section{Effect of $\mathrm{pH}$ of the treating solution on WPG and strength of micro-veneers}

The WPG of veneers treated with $1.2 \mathrm{M} \mathrm{GA}$ and $1.5 \%$ $\mathrm{MgCl}_{2}$ did not change with the $\mathrm{pH}$ of the treating solutions; leaching of the treated veneers, however, caused reduction in WPG to different extents (Figure 1a). The veneers treated at $\mathrm{pH} 4.0$ and 4.5 attained the highest WPG after leaching with up to $80 \%$ fixation of initially absorbed GA. Above $\mathrm{pH}$ 4.5 , the fixation rate decreased with increasing $\mathrm{pH}$ suggesting that the carbonyl reaction with cell wall hydroxyl groups proceeds preferentially at lower $\mathrm{pH}$. Only $20 \%$ of total

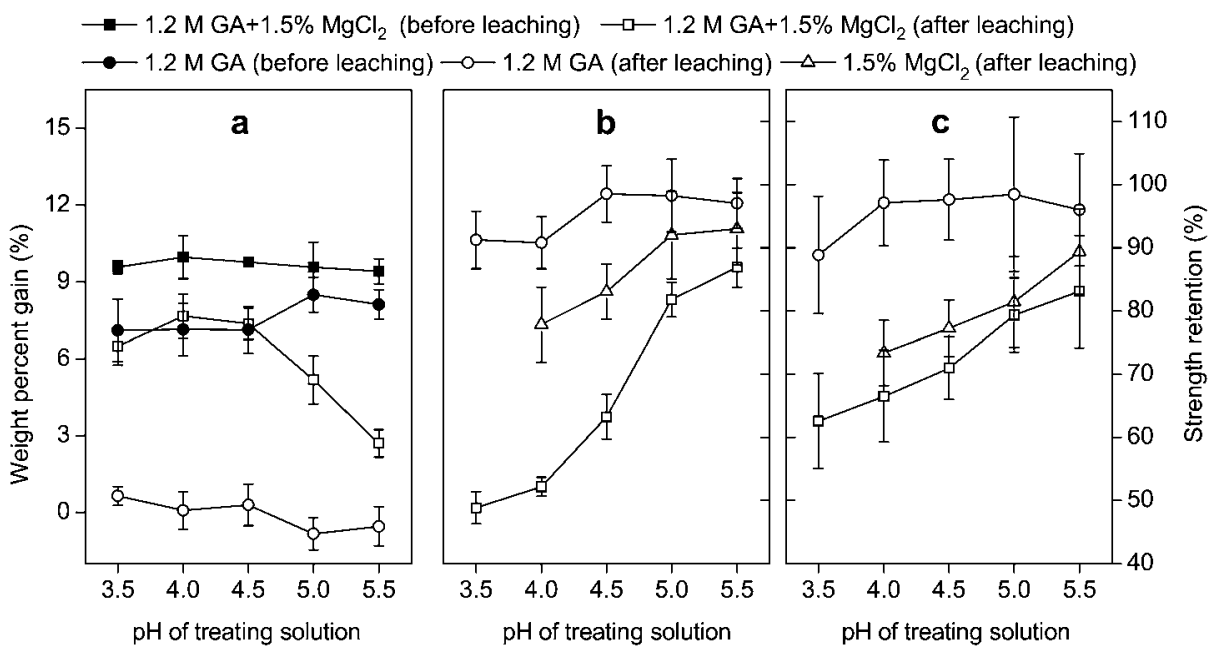

Figure 1 The effect of $\mathrm{pH}$ of the treating solution on tensile properties of thin veneer strips. Weight percent gain (a), zero-span tensile strength (b), and finite-span tensile strength (c) retentions of wood veneers individually treated with $1.2 \mathrm{M} \mathrm{GA}, 1.5 \% \mathrm{MgCl}_{2}$, or combination of both compounds. All values represent mean values $(n=10)$; error bars show standard deviation (SD). 


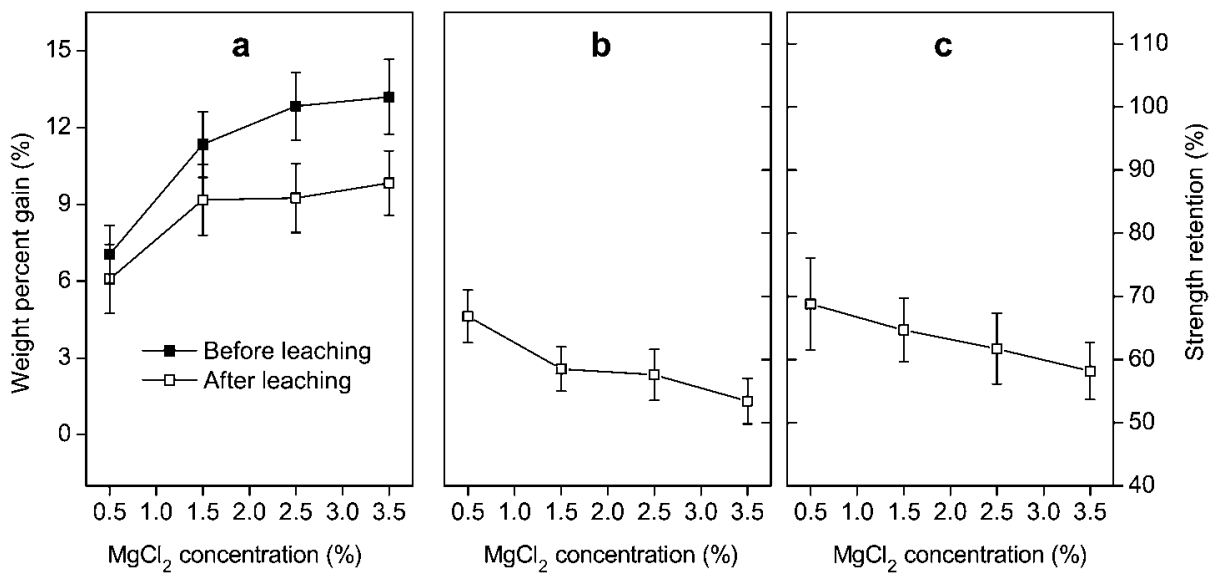

Figure 2 The effect of $\mathrm{MgCl}_{2}$ concentration at fixed GA concentration on the tensile properties of thin veneer strips. Weight percent gain (a), zero- (b), and finite- (c) strength retentions of wood veneers treated with 1.2 M GA and different concentrations of magnesium chloride at $\mathrm{pH}=4.5(\mathrm{n}=10$, mean values $\pm \mathrm{SD})$.

deposited GA remained in specimens treated at pH 5.5 after leaching. The degree of fixation was slightly but not significantly lower at $\mathrm{pH} 3.5$ as compared to $\mathrm{pH} 4.0$ and 4.5.

Specimens treated solely with GA displayed high WPG after treatment, but the absorbed GA was almost completely removed by leaching. This shows that GA did not evaporate during the drying and curing process owing to its high boiling point $\left(188^{\circ} \mathrm{C}\right)$, but did not undergo stable bonding to the cell wall. The catalyst $\mathrm{MgCl}_{2}$ activates $\mathrm{GA}$ and enables reaction with hydroxyl groups. Each aldehyde group can react with one hydroxyl group to form a hemiacetal and subsequently with a second one to form a full acetal. Although the former group is susceptible to hydrolysis, the latter is stable under both neutral and acid conditions (Fujimura and Okamoto 1961; Xu et al. 2004). Thus, it is possible that hemiacetal groups were formed in the presence and absence of $\mathrm{MgCl}_{2}$, but that these groups were cleaved upon leaching. It is assumed that the proportion of hemiacetal is clearly higher in the presence of $\mathrm{MgCl}_{2}$ than in its absence, because of the favored reaction conditions.

Previous studies have revealed that sole treatment with $\mathrm{MgCl}_{2}$ in neutral aqueous solution have a minor effect on wood strength, but under acidic conditions a severe decrease in $\mathrm{Z}$ - and f-strength occurred (Xie et al. 2007). This study shows that a decreasing $\mathrm{pH}$ of the treating solution resulted in a higher strength loss (Figure 1b,c). At $\mathrm{pH} 4.0$, the reduction in $\mathrm{z}$ - and f-strength amounted to approximately $20 \%$ and $25 \%$, respectively. Sole treatment with aqueous GA affected $\mathrm{z}$ - and f-strength only to a minor extent at $\mathrm{pH} 3.5$ (maximum $10 \%$ reduction), but there was no influence above $\mathrm{pH} 4.5$.

Treatment with GA and $\mathrm{MgCl}_{2}$ brought about increased strength losses with decreasing $\mathrm{pH}$ values, whereas $\mathrm{z}$ strength losses were higher than losses in f-strength (Figure $1 \mathrm{~b}, \mathrm{c})$. Both types of strength loss were clearly higher than observed after sole treatment with GA or $\mathrm{MgCl}_{2}$, respectively. Such strength losses could be attributed to two effects: (a) hydrolysis of cell wall polysaccharides catalyzed by $\mathrm{MgCl}_{2}$ thereby resulting in reduction of the degree of polymerization of the cell wall polysaccharides. This catalytic effect could be enhanced by complexation of $\mathrm{MgCl}_{2}$ through GA, which could render the Lewis acid more acidic and explain the higher strength loss as compared to the sole treatment with $\mathrm{MgCl}_{2}$. (b) Strength loss might also be caused by crosslinking of the cell wall matrix through GA; this could make the fibers less elastic and impede any slippage of single microfibril. Crosslinking also results in a reduced freedom of movement of the wood cell wall matrix and restricts the release of mechanical stress under tensile forces (Rowell 1998). Decreasing $\mathrm{pH}$ should result in a higher degree of polysaccharide hydrolysis and of crosslinking. The latter is reflected by the higher WPG after leaching at low $\mathrm{pH}$.

The combined treatment of $\mathrm{MgCl}_{2}$ (above $0.5 \%$ ) and GA (above $0.4 \mathrm{M}$ ) at $\mathrm{pH}$ below 5 caused a stronger loss in $\mathrm{z}$ strength than in f-strength (in all tests, Figures 1-4). Untreated veneers display different failure modes in $\mathrm{z}^{-}$and $\mathrm{f}$ strength testing (Evans and Banks 1988; Xie et al. 2007). Whereas in $\mathrm{z}$-strength testing the fibers (here tracheids) exclusively break itself (intracellular failure), f-strength testing produces a high proportion of fiber separation (intracellular failure) at the compound middle lamellae (CML), which mainly consists of pectin and lignin and which is the weakest cell wall layer. GA treatment, however, could weaken the polysaccharides in the S2 layer to such an extent that the S2 becomes weaker than the CML. In this case, intracellular failures might gain predominance over intercellular failures also in f-strength testing. Therefore, f-strength should be lower than z-strength under static strains, because at finite span there are more possibilities for the failure to occur. The higher strength loss in z-strength, however, can be explained with the testing mode: in f-strength testing the force is statically increased, whereas in z-strength the force is applied in a rapid, dynamical impact (explosion).

Generally, embrittlement of wood as a result of hydrolysis and crosslinking of matrix polymers has a greater influence on dynamic strength properties, such as impact bending strength, than on static properties (see also below), because 

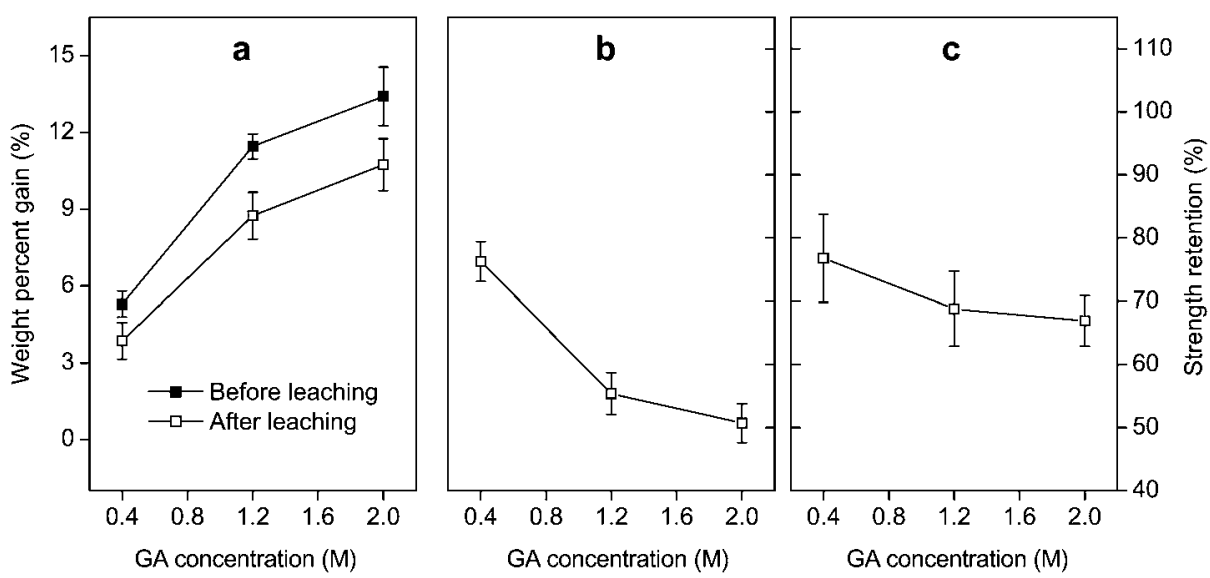

Figure 3 The effect of GA concentration at fixed $\mathrm{MgCl}_{2}$ concentration on the tensile properties of thin veneer strips. Weight percent gain (a), zero- (b), and finite- (c) strength retentions of wood veneers treated with GA and $1.5 \%$ magnesium chloride at $\mathrm{pH}=4.5(\mathrm{n}=10, \mathrm{mean}$ values $\pm \mathrm{SD})$.

the energy absorbed by wood is higher with dynamic rather than with static load. The high increase in z-strength loss after combined treatment as compared to f-strength indicates a significant contribution of crosslinking to z-strength loss, because after sole $\mathrm{MgCl}_{2}$ treatment the loss in $\mathrm{z}$-strength was not higher than that in f-strength.

The results show that the $\mathrm{pH}$ of the treating solution has a considerable influence on the reactivity of GA with wood and on its tensile strength. In the following tests $\mathrm{pH} 4.5$ was preferred owing to high WPG and relatively low strength loss caused. In addition, $\mathrm{pH} 4.5$ is relatively close to the native $\mathrm{pH}$ of pine wood (approximately 5.1 according to Sandermann and Rothkamm 1959).

Comparable z- and f-strength losses as shown in this study have also been reported for veneers treated with DMDHEU and $\mathrm{MgCl}_{2}$ as a catalyst (Xie et al. 2007). In contrast to DMDHEU, GA is not capable of undergoing self-condensation within the cell wall and releases only one water molecule at the formation of a full acetal group. In this study, GA treatment was conducted in such a way as to remove water from the cell wall by pre-drying and, thus, to minimize hydrolysis of cell wall polymers. High strength losses, however, still occurred even with $\mathrm{MgCl}_{2}$ alone indicating that hydrolysis was still an important factor in reducing strength. In addition to crosslinking, further strength losses could be attributable to higher acidity of a $\mathrm{MgCl}_{2}-\mathrm{GA}$ complex or to further release of water during full acetal formation.

\section{Effect of $\mathrm{MgCl}_{2}$ concentration on WPG and strength of micro-veneers}

The WPG of veneers treated with 1.2 M GA after leaching displayed similar high values above $\mathrm{MgCl}_{2}$ concentration of $1.5 \%$ (Figure 2a). This indicates that $\mathrm{MgCl}_{2}$ concentration of at least $1.5 \%$ is required to reach a maximum fixation of GA under these treatment conditions. Both z- and f-strength continuously decreased with increasing concentration of $\mathrm{MgCl}_{2}$ (Figure 2b,c), although the WPG of veneers did not increase above $1.5 \%$ catalyst concentration. As described above, this is attributed to a higher degree of hydrolysis and crosslinking.
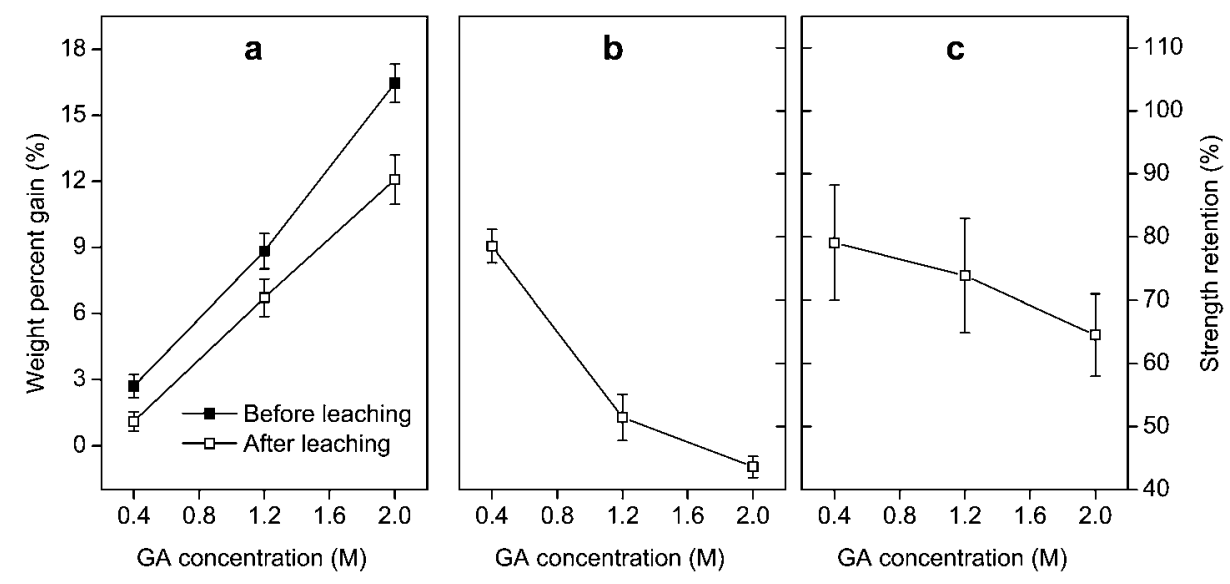

Figure 4 The effect of GA and $\mathrm{MgCl}_{2}$ in a fixed molar ratio of 1:0.06 on the tensile properties of thin veneer strips. Weight percent gain (a), zero- (b), and finite- (c) strength retentions of wood veneers treated with GA and $\mathrm{MgCl}_{2}$ at $\mathrm{pH}=4.5(\mathrm{n}=10$, mean values \pm SD). 


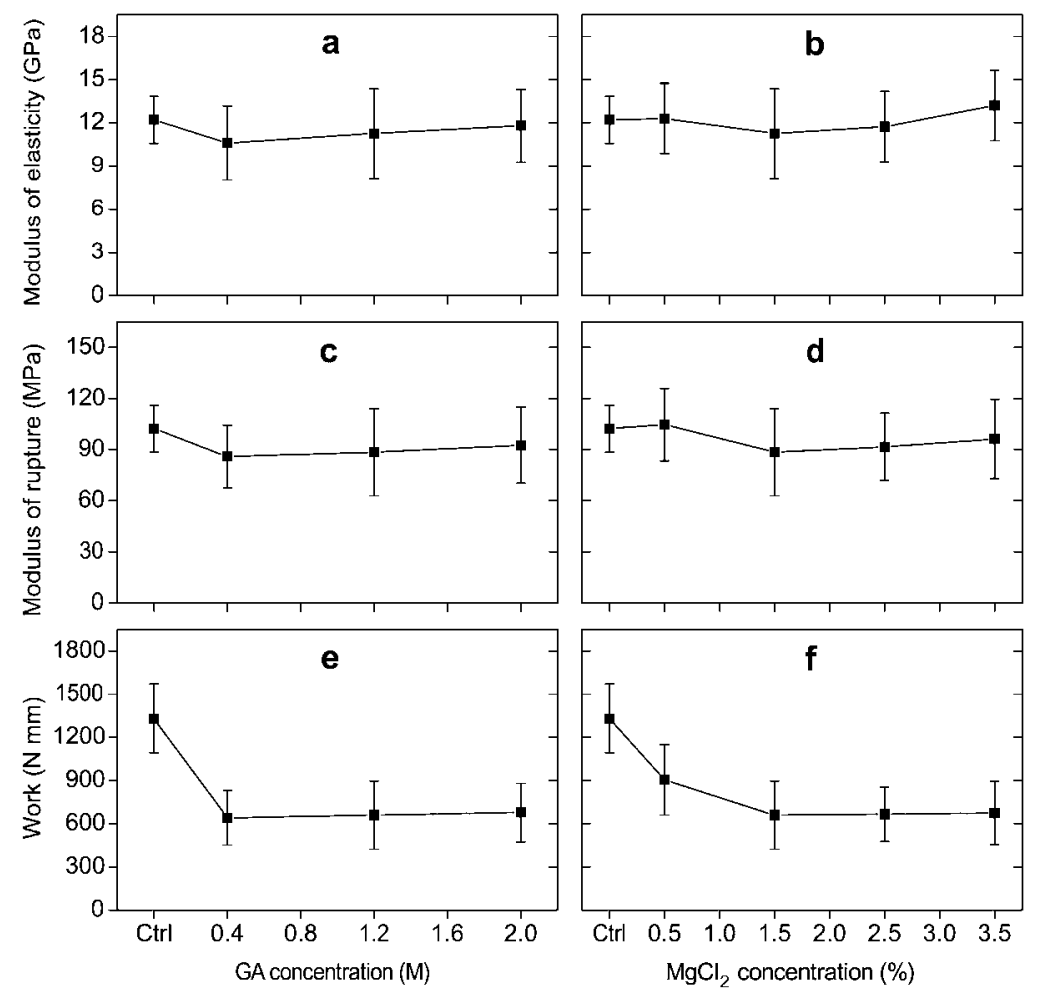

Figure 5 Modulus of elasticity ( $a, b)$, modulus of rupture (c, d), and work to maximum load in bending (e, f) of solid wood stakes treated with buffer alone (Ctrl) and with GA. The effect of GA concentration at fixed $\mathrm{MgCl}_{2}$ concentration of $1.5 \%$ (a, c, e) and the effect of $\mathrm{MgCl}_{2}$ concentration at fixed GA concentration of $1.2 \mathrm{M}(\mathrm{b}, \mathrm{d}, \mathrm{f})$ at $\mathrm{pH}=4.5(\mathrm{n}=10$, mean values $\pm \mathrm{SD})$.

\section{Effect of GA concentration on WPG and strength of micro-veneers}

The WPG of treated veneers increased with increasing concentration of GA in the presence of $1.5 \% \mathrm{MgCl}_{2}$ (fixed absolute concentration) before and after leaching (Figure 3a). Zand f-strength losses of treated veneers also increased with increasing GA concentration (Figure 3b,c). As the catalyst concentration was fixed to $1.5 \%$, the concentration of $\mathrm{MgCl}_{2}$ complexed with GA was assumed to be the same in all treatment solutions provided that the equilibrium constant of the complex formation is high. The degree of hydrolysis should, thus, be similar in all veneers and the differences in strength loss are therefore attributed to crosslinking of the cell wall matrix. Veneers treated solely with $\mathrm{MgCl}_{2}$ exhibited $15 \% \mathrm{z}-$ strength loss and $20 \%$ f-strength loss at $\mathrm{pH} 4.5$ (Figure 1). Low concentration of GA $(0.4 \mathrm{M})$ caused only minor extra strength loss (approximately 5\%). Veneers treated with $2.0 \mathrm{M}$ GA (and $1.5 \% \mathrm{MgCl}_{2}$ ) caused z-strength loss of $50 \%$ and f-strength loss of $33 \%$ (Figure 3b,c). These differences can be explained with differing testing methods and failure modes of wood (see above).

Further treatments were carried out with $\mathrm{GA}$ and $\mathrm{MgCl}_{2}$ in a fixed molar ratio of 1:0.06 to investigate the combined effects of catalyst and GA. WPGs before and after leaching increased linearly with the treatment concentration (Figure 4a). Losses in z- and f-strength (Figure 4b,c) were similar to those of veneers treated with GA and fixed $\mathrm{MgCl}_{2}$ concentration (Figure 3a,b) indicating that the ratio of GA to $\mathrm{MgCl}_{2}$ is not crucial with regard to tensile strength loss in the concentration range tested.

\section{Mechanical properties of solid wood}

Treatment with variable GA and $1.5 \% \mathrm{MgCl}_{2}$ did not change the MOE (Figure 5a) and MOR (Figure 5c) in the bending test of solid wood stakes as compared to the untreated controls. Work to maximum load in bending, however, significantly diminished by approximately $50 \%$ for all treated stakes irrespective of GA concentration (Figure 5e). This shows that the concentration of GA did not influence the degree of strength reduction within the range tested.

The bending properties of stakes treated with 1.2 M GA and variable $\mathrm{MgCl}_{2}$ concentrations were comparable to those treated with variable $\mathrm{GA}$ concentration and $1.5 \% \quad \mathrm{MgCl}_{2}$ (Figure $5 \mathrm{~b}, \mathrm{~d}, \mathrm{f})$. Lowest concentration of $\mathrm{MgCl}_{2} \quad(0.5 \%)$ brought about $32 \%$ reduction in the work to maximum load in bending compared to the controls, but higher catalyst concentrations caused approximately $50 \%$ reduction.

Impact bending strength also significantly diminished by more than $60 \%$ at $0.4 \mathrm{M} \mathrm{GA}\left(1.5 \% \mathrm{MgCl}_{2}\right)$; at a further increase in GA concentration the impact bending strength was unchanged (Figure 6a). With 1.2 M GA and variable $\mathrm{MgCl}_{2}$ concentrations the reduction of impact bending strength was comparable to that of stakes treated with variable GA and $1.5 \% \mathrm{MgCl}_{2}$ (Figure 6b). This shows that within the tested range neither the concentration of GA nor of $\mathrm{MgCl}_{2}$ have an influence on the degree of impact strength 

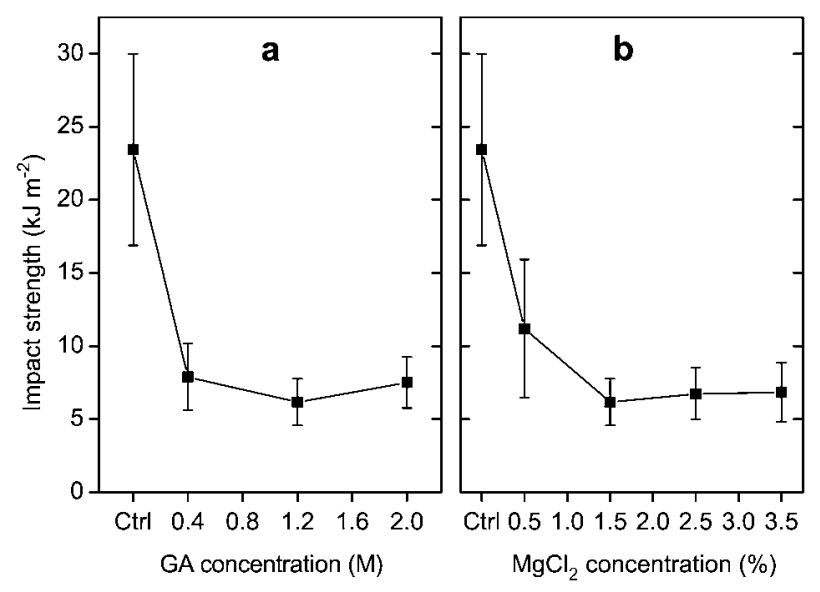

Figure 6 Impact bending strength of solid wood stakes treated with buffer alone (Ctrl) and with GA. The effect of GA concentration at fixed $\mathrm{MgCl}_{2}$ concentration of $1.5 \% \mathrm{MgCl}_{2}$ (a), and the effect of $\mathrm{MgCl}_{2}$ concentration at fixed $\mathrm{GA}$ concentration of $1.2 \mathrm{M}$ (b) at $\mathrm{pH}=4.5(\mathrm{n}=20$, mean values $\pm \mathrm{SD})$.

reduction. Impact bending strength and work to maximum load in bending represent the degree of toughness of wood; in general, the lower the toughness the more brittle is the wood. In contrast to toughness, axial compression strength of wood blocks gradually increased by up to $48 \%$ with increasing GA concentration (Figure 7); this could be due to deposition of GA in the cell wall resulting in increased density.

MOR is influenced by the strength of the single fibers (tracheids in softwood), the strength of the adhesion between the fibers, and the compression strength of wood (Winandy and Rowell 1984). Reduction in tensile strength of veneers measured in z- and f-mode through GA treatment, as shown above, indicates strength losses of single fibers and of adhesion between the fibers as a result of GA treatment.

The unchanged MOR of GA treated stakes could be explained by the fact that the reduction in tensile strength owing to polysaccharide hydrolysis and crosslinking was

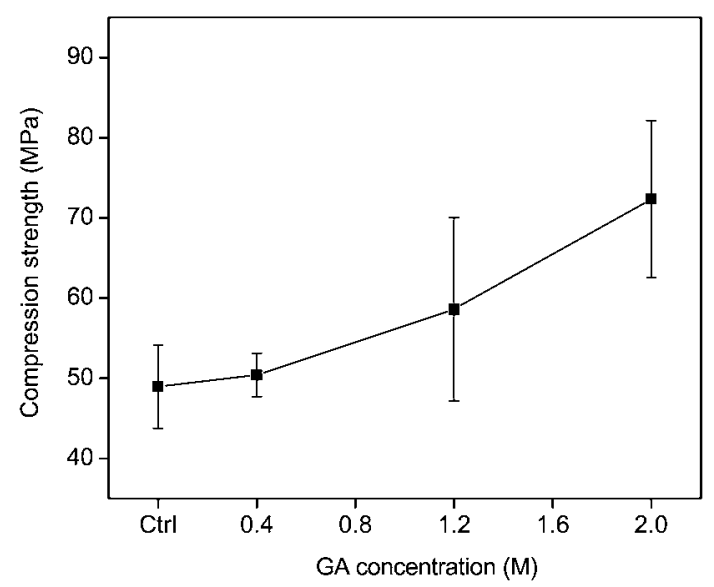

Figure 7 Compression strength axial to the grain of wood blocks treated with buffer (Ctrl), and $\mathrm{GA}$ and $\mathrm{MgCl}_{2}$ at a fixed molar ratio of 1:0.06 at $\mathrm{pH}=4.5(\mathrm{n}=20$, mean values $\pm \mathrm{SD})$. obviously compensated by an increase in compression strength. Polysaccharide hydrolysis and crosslinking also constitute the molecular basis for the embrittlement of wood indicated by severe reduction in work to maximum load in bending and in impact bending strength. Severe brittleness was also observed for formaldehyde-treated wood (Stamm 1959; Burmester 1967; Yano et al. 1986) which can be attributed to the same effects as with GA-treated wood. Furfurylated wood displayed severely reduced toughness owing to hydrolysis of cell wall polysaccharides (Stamm 1977; Westin et al. 2004). The reaction of furfuryl alcohol with lignin was assumed (Westin et al. 2003), but has never been verified. The latter might cause crosslinking and additionally induce brittleness. In contrast, acetylation did not cause considerable losses in dynamic strength properties and tensile strength of micro-veneers (Tarkow et al. 1946; Rowell and Banks 1987). This difference can be explained with the lack of crosslinking in acetylated wood. In addition, acetylation is performed in the absence of water and, thus, hydrolysis occurs in a minor degree. Strength losses owing to hydrolysis might also be compensated by the lower moisture content of acetylated wood at a given RH as compared to untreated wood. GA treatment also reduced the EMC (Yasuda and Minato 1994; Yasuda et al. 1994; Xiao et al. 2009), but the gain in strength was counteracted by the loss as a result of hydrolysis and crosslinking.

\section{Conclusion}

Wood modification with GA has been previously shown to reduce liquid water uptake and vapor sorption, increase dimensional stability, and enhance durability of wood (Weaver et al. 1960; Yasuda and Minato 1994; Yasuda et al. 1994; Xiao et al. 2009). These improvements in wood properties, however, are accompanied with strength losses and embrittlement as a result of hydrolysis and crosslinking of cell wall polymers. The Lewis acid catalyst magnesium chloride and the $\mathrm{pH}$ value of the treating solution appear to play an important role in the processes of strength loss. Slightly acidic $\mathrm{pH}$ (4.5) brought about high WPG and fixation rates and, thus, a high degree of crosslinking, but also induced severe strength losses. The individual contribution of hydrolysis and crosslinking of matrix polymers to strength losses is still unclear. GA treatment did not change bending strength and increased compression strength, but impact bending strength was clearly reduced indicating severe embrittlement. Owing to improvements of water related properties and durability, GA treated wood appears very suitable for application under conditions of outdoor weathering, but the severe reduction in impact strength could limit its utilization in areas where high dynamic strength is required.

\section{Acknowledgements}

Zefang Xiao and Yanjun Xie would like to thank the German Academic Exchange Service (DAAD) for grants. 


\section{References}

Bongers, H.P.M., Beckers, E.P.J. (2003) Mechanical properties of acetylated solid wood treated on pilot plant scale. In: Proceedings of the First European Conference on Wood Modification, Ghent, Belgium. Eds. Van Acker, J., Hill, C.A.S. pp. 341-350.

Bravery, A.F., Grant, C. (1971) Preliminary investigations into the use of a thin strip tensile strength test for the rapid evaluation of wood preservatives against Basidiomycete fungi. Int. Biodetn. Bull. 7:169-173.

Burmester, A. (1967) Tests for wood treatment with monomeric gas of formaldehyde using gamma rays. Holzforschung 21:13-20.

Choi, H.M., Kim, J.H., Shin, S. (1999) Characterization of cotton fabrics treated with glyoxal and glutaraldehyde. J. Appl. Polym. Sci. 73:2691-2699.

Derbyshire, H., Miller, E.R. (1981) The photodegradation of wood during solar irradiation. Part I: effects on the structural integrity of thin wood strips. Holz Roh Werkst. 39:341-350.

Evans, P.D., Banks, W.B. (1988) Degradation of wood surfaces by water. Changes in mechanical properties of thin wood strips. Holz Roh Werkst. 46:427-435.

Evans, P.D., Schmalzl, K.J. (1989) A quantitative weathering study of wood surfaces modified by chromium VI and iron III compounds. Part 1. Loss in zero-span tensile strength and weight of thin wood veneers. Holzforschung 43:289-292.

Evans, P.D., Wallis, A.F.A., Owen, N.L. (2000) Weathering of chemically modified wood surfaces. Natural weathering of Scots pine acetylated to different weight gains. Wood Sci. Technol. 34: 151-165.

Evans, P.D., Owen, N.L., Schmid, S., Webster, R.D. (2002) Weathering and photostability of benzoylated wood. Polym. Degrad. Stabil. 76:291-303.

Frick, J.G., Harper, R.J. (1982) Crosslinking of cotton cellulose with aldehydes. J. Appl. Polym. Sci. 27:983-988.

Fujimura, T., Okamoto, S. (1961) On the acetalization of regenerated cellulose with dialdehydes. J. Polym. Sci. 51:173-183.

Haider, K., Domsch, K.H. (1969) Abbau und Umsetzung von lignifiziertem Pflanzenmaterial durch mikroskopische Bodenpilze. Arch. Mikrobiol. 64:338-348.

Hartley, C. (1958) Evaluation of wood decay in experimental work. Forest Products Laboratory, Madison, WI. Report No. 2119.

Nuessle, A.C., Fineman, M.N., Heiges, E.O.J. (1955) Some controversial aspects of crease resistance of cellulosic fabrics. Textile Res. J. 25:24-40.

Raczkowski, J. (1980) Seasonal effects on the atmospheric corrosion of spruce micro-sections. Holz Roh Werkst. 38:231-234.

Roff, W.J. (1958) A review of the literature relating to the interaction of cellulose and formaldehyde. J. Text. Inst. 49:T646-T663.

Rowell, R.M. (1998) Property enhanced natural fibre composite materials based on chemical modification. In: Science and Technology of Polymers and Advanced Materials. Eds. Prasad, P.N., Mark, J.E., Kandil, S.H., Kafafi, Z.H. Plenum, New York. pp. 717-732.

Rowell, R.M., Banks, W.B. (1987) Tensile strength and toughness of acetylated pine and lime flakes. Br. Polym. J. 19:479-482.

Sandermann, W., Rothkamm, M. (1959) The determination of pH value of commercial woods and its practical importance. Holz Roh Werkst. 17:433-441.

Stamm, A.J. (1959) Dimensional stabilisation of wood by catalysed heat treatment and crosslinking with formaldehyde. Tappi 42 : $44-50$.
Stamm, A.J. (1977) Dimensional stabilization of wood with furfuryl alcohol. In: Wood Technology: Chemical Aspects. ACS Symposium Series, 43. Ed. Goldstein, I.S. American Chemical Society, Washington, DC. pp. 141-149.

Stevens, M., Parameswaran, N. (1981a) Effect of formaldehyde-acid catalysed reactions on wood ultrastructure. Wood Sci. Technol. 15:287-300.

Stevens, M., Parameswaran, N. (1981b) Microscopical analysis of formaldehyde-acid modified wood. Document No. IRG/WP 3182. International Research Group on Wood Protection, Stockholm, Sweden.

Tarkow, H., Stamm, A.J. (1953) Effect of formaldehyde treatments upon the dimensional stabilization of wood. J. Forest Prod. Res. Soc. 3:33-37.

Tarkow, H., Stamm, A.J., Erickson, E.C.O. (1946) Acetylated wood. Forest Products Laboratory, USDA Forest Service, Madison, WI. Report 1593.

Vihavainen, T., Piispanen, K., Mansikkmäki, P. (1980) Treatment of wood with formaldehyde. Acid catalysis of the reaction between formaldehyde and wood. Document No. IRG/WP 3146. International Research Group on Wood Protection, Stockholm, Sweden.

Weaver, J.W., Nielson, J.F., Goldstein, I.S. (1960) Dimensional stabilization of wood with aldehydes and related compounds. Forest Prod. J. 10:306-310.

Westin, M., Lande, S., Schneider, M. (2003). Furfurylation of wood: process, properties and commercial production. In: Proceedings of the First European Conference on Wood Modification, Ghent, Belgium. Eds. Van Acker, J., Hill, C.A.S. pp. 289-306.

Westin, M., Lande, S., Schneider, M. (2004) Wood furfurylation process and properties of furfurylated wood. Document No. IRG/WP 04-40289. International Research Group on Wood Protection, Stockholm, Sweden.

Whipple, E.B., Ruta, M. (1974) Structure of aqueous glutaraldehyde. J. Org. Chem. 39:1666-1668.

Winandy, J.E., Rowell, R.M. (1984) The chemistry of wood strength. In: The Chemistry of Solid Wood. Advances in Chemistry Series No. 207. Ed. Rowell, R.M. American Chemical Society, Washington, DC.

Xiao, Z., Xie, Y., Militz, H., Mai, C. (2009) Effect of glutaraldehyde on water related properties of solid wood. Holzforschung 64 : DOI 10.1515/HF/2010.058.

Xie, Y., Krause, A., Militz, H., Turkulin, H., Richter, K., Mai, C. (2007) Effect of treatments with 1,3-dimethylol-4,5-dihydroxyethyleneurea (DMDHEU) on the tensile properties of wood. Holzforschung 61:43-50.

Xu, G.G., Yang, C.Q., Deng, Y. (2004) Combination of bifunctional aldehydes and poly(vinylalcohol) as the crosslinking systems to improve paper wet strength. J. Appl. Polym. Sci. 93:1673-1680.

Yano, H., Yamada, T., Minato, K. (1986) Changes in acoustical properties of Sitka spruce due to reaction with formaldehyde. Mokuzai Gakkaishi 32:984-989.

Yasuda, R., Minato, K. (1994) Chemical modification of wood by non-formaldehyde cross-linking reagents. Part 1. Improvement of dimensional stability and acoustic properties. Wood Sci. Technol. 28:101-110.

Yasuda, R., Minato, K., Norimoto, M. (1994) Chemical modification of wood by nonformaldehyde cross-linking reagents. Part 2. Moisture adsorption and creep properties. Wood Sci. Technol. 28:209-218.

Received December 20, 2009. Accepted February 5, 2010. Previously published online May 18, 2010. 